provinces of China proper with the districts in India corresponding nearly in physical characteristics and cultivable area, and, summarising these computations, he found that, over a total area of $1,500,650$ square miles, the population, according to this estimate from the Indian averages, would be $282, \mathrm{r} 6 \mathrm{r}, 923$, or, say, 183 persons to the square mile, while the latest official returns obtained from China show $349,885,386$, or 227 inhabitants to the square mile. The general conclusion, he said, might be that the latest Chinese returns, though probably in excess of the reality, did not seem to be extravagant or incredible on the whole if tested by the known averages of the Indian census.

\section{THE FORMS OF LEAVES}

SIR JOHN LUBBOCK said that, greatly as we all appreciated the exquisite loveliness of flowers, we must admit that the beauty of our wools and fields was as much due to the marvellous grace and infinite variety of foliage. How is this inexhaustible richness of forms to be accounted for? Does it result from an innate tendency of the leaves in each species to assume some particular shape? Has it been intentionally designed to delight the eyes of man? Or has it reference to the structure and organisation, the wants and requirements of the plant itself?

Now, if we consider first the size of the leaf, we shall find that it is regulated mainly with reference to the thickness of the stem. This was shown, for instance, by a table giving the leaf area and the diameter of stem of the hornbeam, beech, elm, lime, Spanish chestnut, ash, walnut, and horse-chestnut. When strict proportion is departed from, the difference can generally be accounted for.

The size once determined exercises much influence on the form. For instance, in the beech the leaf has an area of about 3 square inches. The distance between the buds is about $\mathbf{I}_{4}^{1}$ inches, and the leaves lie in the general plane of the branch, which bends slightly at each internode. The basal half of the leaf fits the swell of the twig, while the upper half follows the edge of the leaf above, and the form of the inner edge being thus determined decides that of the onter one also. In the lime the internodes are longer and the leaf consequently broader. In the Spanish chestnut the stem is nearly three times as stout as that of the beech, and consequently can carry a larger leaf surface. But the distances between the buds are often little greater than those in the beach. This determines, then, the width, and, by compelling the leaf to lengthen itself, leads to the peculiar form which it assumes. Moreover, not only do the lcaves on a single twig admirably fit one another, but they are also adapted to the ramification of the twigs themselves, and thus avail themselves of the light and air, as we can see by the shade they cast without large interspaces or much overlapping.

In the sycamores, maples, and horse-chestnuts the arrangement is altogether different. The shoots are stiff and upright, with leaves placed at right angles to the plane of the branch, instead of being parallel to it. The leaves are in pairs, and decussate with one another, while the lower ones have lons petioles, which bring them almost to the level of the upper pairs, the whole thus forming a beautiful dome.

For leaves arranged as in the beech, the gentle swell at the base is admirably suitcd; but in a crown of leaves, such as those of the sycamore, space would be thereby wasted, and it is better that they should expand at once, as soon as their stalks have carried them frce from the upper and inner leaves. Hence we see how beautifully the whole form of these leaves is adnpted to the mode of growth and arrangement, of the buds in the plants themselves.

In the black poplar the arrangement of the leaves is again quite different. The leaf-stalk is flattencl, so that the lcaves hang vertically. In connection with this it will be observed that, while in most leaves the upper and under surfaces arc quito unlike, in the black poplar, on the contrary, they are very simi lar. The stomata or breathing-holcs, moreover, which in the leaves of most trees arc confined to the under surface, are in in this species nearly equally numerous on both. The "compass" plant of the American prairies, a yellow composite not unlike a small sunfower, is another plant with upright leaves, which, growing in the wide open prairies, tend to point north and south, thus exposing both surfaces equally to the light and

${ }^{x}$ Abstract by the Author of a Lecture delivered at the Royal Institute,
Feb. 13 by Sir John Lubbock, Bart., M.P., D.C.L., LL.D., F.R.S., \&c. heat. It was shown by diagrams that this position also affected the internal structure of the leaf.

In the yew the leaves are inserted close to one another, and are long and linear; while in the bux they are further apart and broader. In the Scotch fir the leaves arc linear, and $x$ inch long; while in other pines, as, for instance, the Weymouthin, the stem is thicker and the leaves longer.

In the plants hitherto mentioned one main consideration appears to be the secuting of as much light as possible; but in tropical countries the sun is often too powerful, and the leaves, far from courting, avoid the light. The typical acacias have primate leaves, but in most Australian species the true leaves are replaced by a vertically flattened leaf-stalk. It will be found, however, that the scedlings have leaves of the form typical in the genus. Gradually, however, the leaf becomes smaller and smaller, until nothing is left but the flattened leafstalk or phyllode. In one species the plant throughout life produces both leaves and phyllodes, which give it a very curious and interesting appearance. In encalyptus, again, the young plant has horizontal leaves, which in olcler ones are replaced by scimitar-shaped pliyllodes. IIence the different appearances of the young and oll trees which must have struck every visitor to Algiers or the Riviera.

We have hitherto been considering mainly deciduous trees. In evergreens the conditions are in many respects different. It is generally said that leaves drop off in the autumn because they die. This, however, is not strictly correct. 'The fall of the leaf is a vital process connected with a change in the cellular tissues at the hase of the leaf-stalk. If the leaves are killed too soon they do not drop off. Sir Jolnn illustrated this by some twigs which he had purposely broken in the summer; below the fracture the leaves had been thrown off, alrove they still adhered, and so tightly that they could support a considerable weight. In evergreen trees the conditions are in many respects very different. It is genexally supposed that the leaves last one complete year. Many of them, however, attain a much greater age: for instance, in the Scotch fir, three or four years; in the spruce and silver, six or seven; in the yew even longer. It follows from this that they require a tougher and more healthy texture. When we have an early fall of snow our deciduous trees are often much broken down; glossy leaves have a tendency to throw it off, and thus cscape, hence evergreen leaves are very generally smooth and glossy. Again, evergreen leaves often have special protection either in an astringent or aromatic taste, which renders them more or less inedible ; or by thorns and spines. Of this the holly is a familiar illustration; and it was pointed out that in old plants alove the range of browsing quadrupeds, the leaves tend to lose their spines and become unarmed. The hairs on leaves are another form of protection; on herbs the presence of hairs is often associated with that of honey, as they protect the plants from the visits of creeping insects. Fence perhaps the tendency of water species to become glabrous, Polysonum anthibium being a very interesting case, since it is hairy when growing on land, and smooth when in watcr. Sir John then dealt with cases in which one species mimics another, and exhibited a striking photograph of a group of stinging nettles and dead nettles, which were so much alike as to be hardly distinguishable. No one can doubt that the stinging nettle is protecter by its poisonous hairs, and it is cqually clear that the innocuous dear nettle must profit by its similarity to its dangerous neighbour. Other similar cases were cited.

He had aiready suggested one consideration, which in certain cascs determined the width of leaves; but there were others in which it was due to different canses, one being the attitude of the leaf itself. In many genera with broad and narrow-leaved species, drosera and plantago, for instance, the broad leaves formed a horizontal rosette, while the narrow ones were raised upwards, Fleshy leaves were principally found in hot and dry countries, where this peculiarity had the advantage of offering a smaller surface, and therefore exposing the plant less to the loss of water by cvaporation.

Sir John then passer to aquatic plants, many of which have two kinds of leaves : one more or less rounded, which floats on the surface; and others cut up into narrow filaments, which remain below. The latter thus presents a greater extent of surface. In air, however, such leaves would be unable to support even their own weight, much less to resist any force such as that of the wind. In perfectly still air, however, for the same reason, finely divided leaves may be an advantage, whereas in 
comparatively exposed situations more compact leaves may be more suitable. It was pointed out that finely cut leaves are common among low herbs, and that some families which among the low and herbaceous species have such leaves, in shrubby or ligneous ones have leaves more or less like those of the laurel or beech.

Much light is thrown on the subject by a study of the leaves of seedlings. Thus the furze has at first trifoliate leaves, which gradually pass into spines. This shows that the furze is descended from ancestors which had trifoliate leaves, as so many of its congeners have now. Similarly, in some species which when mature have palmate leaves, those of the seedling are heart-shaped. $\mathrm{He}$ thought that perhaps in all cases the palmate form was derived from the heart-shaped. He then pointed out that if there were some definite form told off for each species then a similar rule ought to hold good for each genus. The species of a genus might well differ more from one another than the varieties of any particular species; the generic type might be, so to say, less closely limited ; but still there ought to be some type characteristic of the genus.

He took, then, one genus, that of Senecio (the groundsel). Now in addition to Senecios more or less re:embling the common groundsel, there were species with leaves like the daisy, bushy species with leaves like rosemary and the box, small trees with leaves like the laurel and the poplar, climbing species like the convolvulus and bryony. In fact the list is a very long one, and shows that there is no definite type of leaf in the genus, but that the form in the various species depends on the condition of the species. From, these and other considerations he concluded that the forms of leaves did not depend on any inherent tendency, but to the structure and organisation, the habits and requirements of the plant. Of course it might be that the present form had reference to former and not to present conditions. Nor did it follow that the adaptation need be perfect. The tendency existed, just as water tends to find its level. This rendered the problem all the more complex and difficult.

The lecture was illustrated by numerous diagrums and specimens, and Sir John concluded by saying the subject presented a wide and interesting field of study, for if he were correct in his contention every one of the almost infinite forms of leaves must have some cause and explanation.

\section{SCIENTIFIC SERIALS}

Journal of the Russian Chemical and Physical Society, vol. xvi. fasc. 8.- On the oxidation of acetones, by E. Wagner (first paper dealing with their behaviour towards chromic acid). - On the specific volumes of chlorine, iodine, and bro nine in organic compounds, by M. Schalfejeff (second paper). For chlorine they gradually rise with the increase of the number of equivalents entering into combination, gradually reaching 21,24 , and 27 ; for bromine they are 24,27 , and 30 ; and for iodine, 26 to 27 . - Adclition of methylamine to methylglycidic acid, by M. Zelinsky. On Astrakhanite, by W. Markovnikoff.-On the influence of the lineary compression of iron, steel, and nickel rods on their magnetism, by P. Bakmetieff. From a varied series of experiments the author arrives at a series of conclusions, showing that compression of iron rods exercises a very notable influence on their magnetisation, and that the phenomena depend upon the rods having been, or not, formerly submitted to repeated compression; all kinds of iron and steel display the influence of compression-soft iron and steel at a higher degree than hard iron and steel. The theory of rotating molecular magnets would explain all observed phenomena.-On an amperometre based on the electrothermic phenomenon of Pellctier, by N. Hesehus. On the regular forms taken by powders, by. Th. Petrushevsky (second paper dealing with the shapes taken by heaps of powders on surfaces limited by curves, or polygones with entering angles).-Also on the dilatation of liquids; an answer to Prof. Arenarius, by D. Mendeleeff.-An answer to M. Rogovsky, by B. Stankewitsch.-An answer to M. Sokoloff, by M. Bardsky, being a further mathematical inquiry into the forces of molecular attraction.-An answer to M. Petroff, by M. Kraevitsch.--We notice an innovation in this fasciculum of the Journal. It contains detailed minutes of the proceedings of the Physical and Chemical Section of the Moscow Society of Lovers of Natural Science.
Sitzungsberichte der Physicalisch-medicinishen Societät zu Erlangen, No. 16, October, I883, to October, 1884.--Remarks on the phenomenon of phosphorescence in connection with the description of an instrument designed for studying the effect of the various spectral rays, and especially the ultra-red on phosphorising substances, by E. Lommel.- On the fluorescence of calcspar, by E. Lommel.-On the reduction of algebraic differential expressions to normal forms, by M. Noether.-Contributions to the knowledge of the Chytridiaceæ and other fungoid organisms, with thirty-seven illustrations, by D. C. Fisch. -On the malaria and intermittent fevers of the Erlangen district, by Prof. F. Penzoldt. - On the presence of microscopic organisms in the tissues of animals in the normal state, by Dr. Hauser.Test of the sensitiveness of the visual organ to direct and oblique luminous rays, by Dr. Louis Wolftberg.-On algebraic differential expressions, and on Jacobi's reverse problem, by $\mathbf{M}$. Noether.-On the systematic position of the yeast fungus, by M. Reess. - On two new species of Chytridiacex, by C. Fisch. - On the nerves of temperature and touch in the animal system, by $\mathrm{J}$. Rosenthal.- - On a means of determining the quantity of carbonic acid present in the atmosphere of rooms, by J. Rosenthal.-On the phenomenon of Uræmia, by Dr. R. Fleischer.--Toxicologic researches from the physiological standpoint, by J. Rosenthal.On vertigo caused by intestinal affections, by W. Leube.-Experiments on the hatching of bird's eggs whose shells had suffered lesion, by Prof. L. Gerlach.--On Oidema, by Dr. R. Fleischer. -On the surgical operation of opening the mastoid process, by Dr. W. Kiesselbach.-On the life-history and pathological properties of a species of bacteria causing putrefaction, by Dr. G. Hauser.-On the histiology of primary carcinom in the osseous system, by Dr. von Diiring. - On a case of lingual tuberculosis, by Dr. Ernst Graser.-On the after-treatment of external urethrotomy, by H. Knoch.

Rivista Scientifico-Industriale, December 31, 1884.-On the electric conductivity of the alcoholic solutions of some chlorides, by $D_{i}$. Joseph Vicentini.-Memoir on the variations in the electric resistance of solid and pure metal wires according to the temperature (continued), by Prof. Angelo Euro.

\section{SOCIETIES AND ACADEMIES LONDON}

Royal Society, February 12.- "On Underground Tem. peratures, with Observations on the Conductivity of Rocks, on the Thermal Effects of Saturation and Imbibition, and on a Special Source of Heat in Mountain Ranges." By Joseph Prestwich, M.A., F.R.S., Professor of Geology in the University of Oxford.

The author remarks on the difference of opinion between physicists and geologists respecting the probable thickness of the outer crust of the earth-the former on the strength of its great rigidity and the absence of tides, contending for a maximum thickness and comparative solidity of the whole mass; while the latter, in general, on the evidence of volcanic action, the crumpling and folding of the strata in mountain ranges, its general flexibility down to the most recent geological times, and the rate of increase of temperature in descending beneath the surface, contend for a crust of minimum thickness as alone compatible with these phenomena.

'The question of underground temperature, which is a subject equally affecting the argument on both sides, had engaged the author's attention in connection with an inquiry respecting volcanic action, and he was induced to tabulate the results to see how far the usually received rates of increase were affected by various interfering causes - not that most of them had not received due attention, but it was a question whether sufficient allowance had been made for them.

Although Gensanne's first experiments were made in 1740 , and others were subsequently made by Daubuisson, Saussure, and Cordier, in coal and other mines, it was not until the construction of deep artesian wells commenced in the second quarter of this century, and Walferdin introduced his overflow thermo. meter, and precautions were taken against pressure, that the more reliable observations were made and admirably discussed by Arago. The Coal Commission of 1866 collected a mass of important evidence bearing on the question, and in $1867 \mathrm{a} \mathrm{Com}$. mittee of the British Association was appointed to collect further information. Under the able superintendence of Prof. Everett, a series of valuable experiments with improved instruments has 